\title{
Reflexões e fragilidades sobre a Demanda Bioquímica de Oxigênio $(D B O)$ em rios
}

\section{Ellen Cristina de Oliveira Almeida Caroline Kozak Luciane Lemos Prado Cristovão Scapulatempo Fernandes}

\section{RESUMO}

A Demanda Bioquímica de Oxigênio (DBO) representa um dos principais parâmetros de qualidade da água $\mathrm{e}$ de referência para a aplicação dos instrumentos de Gestão de Recursos Hídricos conforme instituído na Política Nacional de Recursos Hídricos (PNRH). No entanto, pouco se tem discutido sobre a padronização analítica, a subjetividade dos métodos empregados, os potenciais erros e limitaçôes de sua determinaçâo, bem como o impacto de sua utilização para a gestão quali-quantitativa em corpos hídricos. Neste contexto, esta pesquisa contribui para estabelecer elementos de reflexão e bases para uma análise crítica sobre do método aplicado a DBO. Dois métodos foram analisados com ênfase am avaliaçáo das incertezas associadas às medidas de qualidade: Winkler e Respirométrico, ambos previstos pelo padróes de parâmetros analíticos de Qualidade da Água.

Palavras-chave: Incertezas analíticas; Gestão de Recursos Hídricos; Rio Iguaçu.

\section{ABSTRACT}

The BOD represents one of the main water quality parameters and reference for a management tools application established by the National Water Resources Policy. Nonetheless, a few studies have been done about the analytical standardization, potential errors and limitations, subjectivity of the methods applied, potential errors and limitations of the determination, as well as the impact in a qualiquantitative management. In this context, this paper aim to determine reflection elements and basis for one critical analyze of the method applied for assessing BOD. The methods studied were Winkler and Respirometric, presenting a discrepancy between the results obtained by the same parameter at the same sampling point.

Key-words: Analytical uncertainties; Water Resources Management; Iguaçu river.

\section{INTRODUÇÃO}

Um dos principais parâmetros de qualidade da água utilizados para avaliar o impacto de efluentes domésticos ou industriais sobre corpos receptores é a Demanda Bioquímica de Oxigênio (DBO) (SANTOS; SALES; DUARTE, 2003). A DBO é um parâmetro quantitativo que determina de forma indireta a concentração de matéria orgânica biodegradável através da demanda de oxigênio exercida por microrganismos na respiraçáo (VALENTE;
PADILHA; SILVA, 1997) para a decomposição da matéria orgânica. Reflete, portanto, no consumo de oxigênio, através de reações de biodegradação da matéria orgânica, e, portanto uma medida indireta da quantidade de matéria orgânica, que é essencialmente simples do ponto de vista conceitual e com muita facilidade para a sua aplicação.

O consumo de oxigênio dissolvido (OD) está relacionado à presença de matéria orgânica em um corpo d'água. $\mathrm{O}$ decréscimo de $\mathrm{OD}$, causado pela respiração dos microorganismos, tem diversas impli- 
cações do ponto de vista ambiental, constituindo um dos principais problemas de poluição das águas, em especial para a realidade brasileira, notadamente caracterizada por um baixo percentual de atendimento de tratamento de esgoto.

O restabelecimento desse equilíbrio após as alteraçôes induzidas pelos despejos de efluentes está relacionado com o fenômeno de autodepuração (VON SPERLING, 2005), o que, em tese, explica a institucionalizaçáo conceitual de que o rio ou corpo receptor pode ser entendido como uma unidade de tratamento de efluentes. O desafio se estabelece na medida em que ainda existem processos associados à depleção de oxigênio, vinculados às demandas no leito de lodo e a demanda de oxigênio do sedimento (CHAPRA, 1997).

Nesse sentido, a legislação brasileira avança ao estabelecer a necessidade de se haver um limite de despejo de efluentes a ser lançado no corpo receptor. A Lei Federal no 9.433/97 instituiu a Política Nacional de Recursos Hídricos (PNRH) a fim de assegurar a qualidade e disponibilidade de água, bem como fornecer instrumentos para a gestáo integrada dos recursos hídricos.

Como um dos instrumentos de gestão previstos na legislação, destaca-se o enquadramento, com o objetivo de estabelecer a classificação de um corpo d'água em classes de uso dos recursos hídricos, em acordo com o proposto pela Resolução CONAMA no 357/2005, através de diretrizes de lançamento e limites permitidos para cada classe.

Neste contexto, a DBO destaca-se como um dos principais parâmetros utilizado para fins legais, justamente por sua praticidade e facilidade de execução analítica. Complementarmente à DBO, existem outros parâmetros de qualidade de água que podem quantificar de forma direta e abrangente a fração de matéria orgânica presente em um corpo hídrico, como por exemplo, o carbono orgânico total (COT) (LEENHEER; CROUÉ, 2003).

No entanto, segundo Knapik (2014), o problema relativo à análise de DBO está relacionado à subjetividade dos métodos analíticos, considerando que a quantidade de oxigênio consumido dependerá de fatores difíceis de serem rigorosamente controlados e comparados, mesmo através de ensaios padróes certificados e estabelecidos em consenso por técnicas analíticas previstas no Standard Methods for the Examination of Water and Wastewater (APHA, 2012).

Para se medir DBO em rios, o método mais utilizado é o normalizado (método 4500-OC), atualmente denominado como teste de frasco fechado, ou Winkler (APHA, 2012). Apesar do uso frequente do teste normalizado, este possui algumas limitaçóes, como: (i) a realização deve ocorrer imediatamente após a coleta para que a sua representatividade seja garantida; (ii) em amostras muito poluídas é necessário realizar uma diluição com água de diluição específica, para garantir a adequada proporçáo de nutrientes e oxigênio disponíveis para o consumo dos microorganismos durante o período de incubação e diminuir os efeitos os organismos nitrificantes, (iii) é medido apenas o OD necessário pelos microorganismos durante o processo de oxidação bioquímica da matéria orgânica presente na amostra; (iv) limite mínimo de detecção, o qual exige que no final do quinto dia de análise a amostra tenha a concentraçáo de $2 \mathrm{mg} \mathrm{O} 2$ $\mathrm{L}^{-1}$, (v) ensaio analítico de 5 dias (em ambiente controlado à $20^{\circ} \mathrm{C}$ ) é o tempo mínimo necessário para se obtenção de resultados. Neste sentido, Metcalf e Eddy (1991) avaliam que dentre as limitaçóes mencionadas, a mais crítica está associada com o período de 5 dias do ensaio. Esse tempo pode ou náo ser suficiente para que a matéria orgânica solúvel presente tenha sido de fato, consumida, visto que neste período, o valor medido está associado a 60-70 \% da oxidação e para valores mais representativos como 95-99\%, o ensaio mínimo seria de 20 dias (METCALF; EDDY, 1991), tornando a logística analítica ainda mais limitada.

Outro método utilizado para mensuração da DBO5 é o método respirométrico (comercialmente conhecido por método do Oxitop). O método consiste na medição direta do consumo de oxigênio pelos microorganismos oxidantes da matéria orgânica biodegradável (APHA, 2012). O consumo de oxigênio produz $\mathrm{CO}_{2}$, o qual é absorvido por cápsulas de $\mathrm{NaOH}$, criando uma pressão negativa.

A diferença de pressão é lida como $\mathrm{DBO}(\mathrm{mg} / \mathrm{L})$. $\mathrm{O}$ ensaio deve ser realizado em frascos fechados em ambiente sob condiçóes constantes de temperatura $\left(20^{\circ} \mathrm{C}\right)$ e agitação. (APHA, 2012). O método respirométrico apresenta algumas vantagens em relação ao método normalizado, entre as quais destacam-se: (i) a maior acurácia e adaptabilidade em medir as 
taxas de consumo de oxigênio; e (ii) a possibilidade de múltiplo processamento das amostras em laboratório (CALDWELL; LANGELIER, 1948) com menos material. Entretanto, as limitaçóes relacionadas com o tempo de processamento e efeito da diluição ainda persistem. Adicionalmente, também existem as flutuaçóes na pressão barométrica do respirômetro utilizado (APHA, 2012) que sempre devem ser verificadas.

Jouanneau et al. (2013) descrevem algumas características técnicas dos principais métodos para quantificação da DBO, como: (i) o método fotométrico; (ii) utilização de biossensores; (iii) células de combustível microbiano (MFC) e (iv) biorreatores. Cada método possui vantagens e desvantagens associadas à disponibilidade no mercado, abundância de publicaçóes sobre o assunto, estreita e variável faixa de medição e quantificação indireta.

A escolha do método, mais adequado, portanto, deve levar em consideração a taxa de erro tolerado, a frequência de medição, a natureza das matrizes e o tipo de aplicação. No entanto, não há na literatura referências claras sobre as limitaçôes, peculiaridades e vantagens que permita comparar os diferentes métodos, em especial, no que concerne às aplicaçóes em gestão de recursos hídricos.

Complementarmente às medidas de DBO, é possível calcular o coeficiente $\mathrm{k}_{1}$, que é uma taxa de decaimento que reflete a degradação da matéria orgânica (ou em outras palavras o consumo de oxigênio dissolvido), muito relevante para entendimento do impacto sobre os sistemas de recursos hídricos. Os valores típicos de $\mathrm{k}_{1}$ variam de 0.05 a $0.5 \mathrm{~d}^{-1}$, com um período de 5 dias para os ensaios de DBO serem realizados (CHAPRA, 1997).

O coeficiente $\mathrm{k}_{1}$ é dependente das características da matéria orgânica, bem como da temperatura e da presença de substâncias inibidoras da atividade biológica. Efluentes que já passaram por um tratamento prévio, possuem uma taxa de degradação mais vagarosa, visto que a remoção de grande parte da matéria orgânica lábil já foi realizada, restando apenas a fração semi-lábil e refratária, de estabilização mais lenta. (BARROS et al., 2011).

Diversas pesquisas em gestão de recursos hídricos envolvendo aspectos de diagnósticos de qualidade da água, modelagem matemática de parâmetros de qualidade da água e gestão de recursos hídricos (KOZAK,
2016; COELHO, 2015; KNAPIK, 2014; KNAPIK, 2009; KONDAGESKI, 2008; PRZYBYSZ, 2007) tem sido estabelecidas como base para Planos de Gestâo de Recursos Hídricos. No entanto, muito pouco se tem discutido sobre a padronização analítica, potenciais erros e limitaçóes, e o impacto para a aplicação dos instrumentos de gestão de recursos hídricos. Nesta pesquisa, uma reflexão é estabelecida neste contexto, justamente para inserir a relevância desta questão na gestão quali-quantitativa em recursos hídricos.

\section{SÉRIE HISTÓRICA DE MONITORAMENTO E OS DESAFIOS ENVOLVIDOS}

\section{A Bacia do Alto Iguaçu}

O monitoramento de pontos na Bacia do Alto e Médio Iguaçu vem sendo realizado desde 2003 (Fernandes et al, 2016) em 10 pontos (IG1 a IG9, sendo que no ponto IG2 foram coletadas nas margens esquerda e direita) ao longo do Rio Iguaçu, além de 13 pontos em quatro afluentes da margem direita (Palmital, Atuba, Belém e Barigui), totalizando 56 coletas de campo (2005-2016) e 23 pontos de monitoramento (Figura 1).

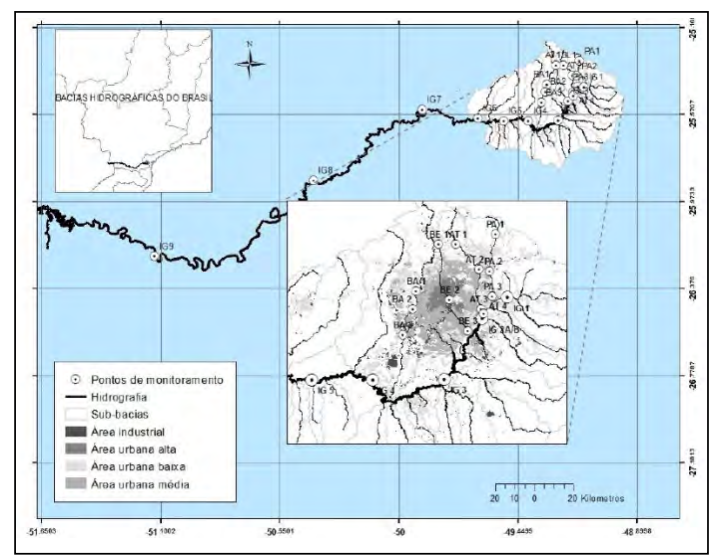

\section{Figura 1 - Pontos de monitoramento do Proje- to INTEGRA 2, ao longo do Rio Iguaçu.}

$\mathrm{Na}$ figura 2, em anexo, estão apresentados os resultados de DBO através das medidas de sua variáveis espaciais e temporais, apresentados por Box-Plots para os pontos de monitoramento do rio Iguaçu (IG1 a IG9 respectivamente), obtidos a partir da série históri- 


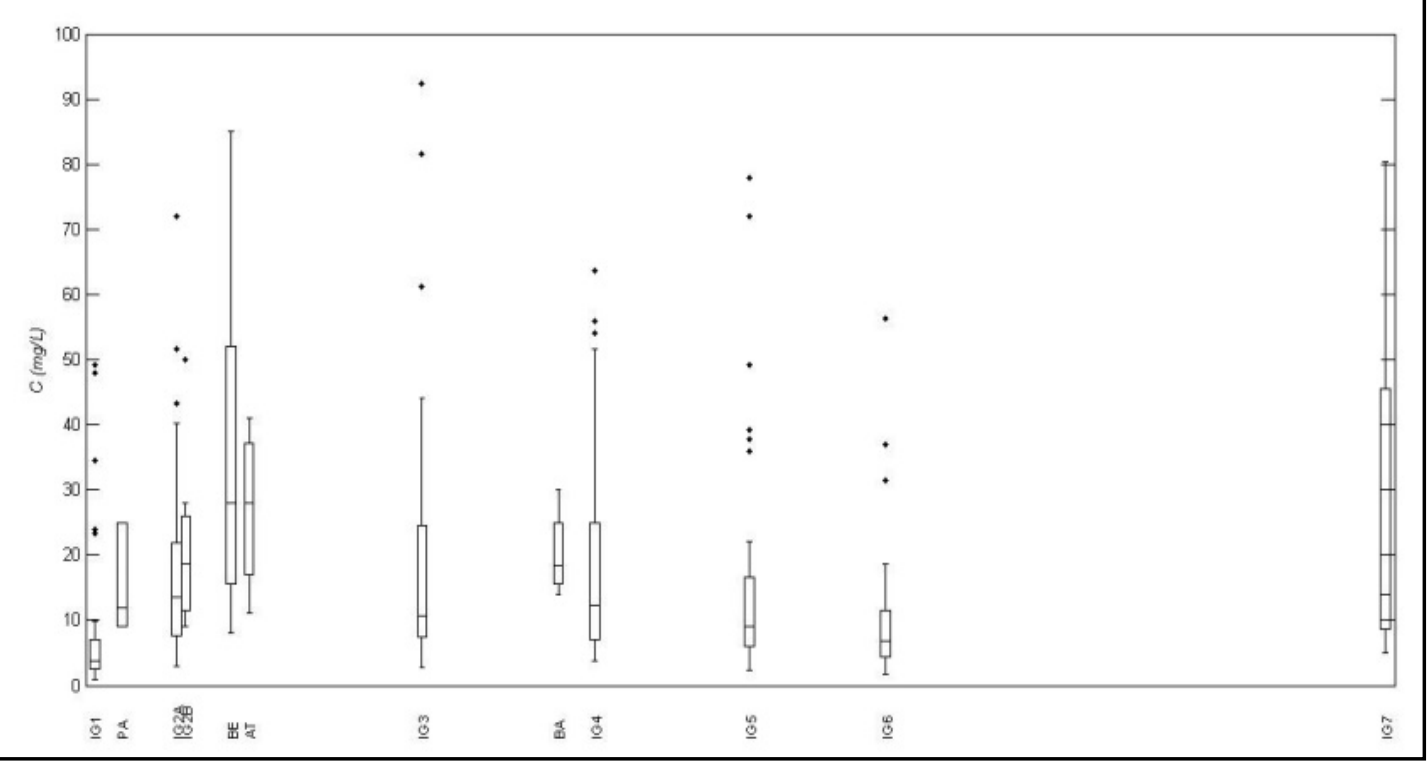

Figura 2 - Boxplot para dados de DBO do Rio Iguaçu ao longo do IG1 (cabeceira) até IG9

ca de DBO, para o período 2003-2016, com destaque para a grande variabilidade temporal observada.

O desafio de entender esta característica, em especial considerando a natureza hidrológica sempre peculiar de uma bacia urbana serviram de base para estabelecer elementos de reflexão, em especial, para a avaliação da DBO no contexto da gestão quali-quantitativa.

Estabeleceram-se, então, procedimentos e discussōes para se avaliar as fragilidades, vantagens e aplicações da determinação do parâmetro DBO. Em laboratório, propôs-se a realização de uma amostragem-teste em três pontos de coleta, para avaliar os dois métodos mais utilizados: normalizado e respirométrico. O objetivo foi: (i) acompanhar o consumo diário de oxigênio dissolvido nas amostras, a fim de verificar as diferenças na quantificação de DBO para os diferentes métodos e (ii) calcular a taxa de decaimento da matéria orgânica (k1) a partir de cada método.

\section{Particularidade da área de estudo}

Para a consecução dos objetivos desta pesquisa, três pontos foram selecionados para as amostragens: (i) os das margens direita (IG2D) e esquerda (IG2E) da seção de monitoramento do rio Iguaçu; (ii) PE1, no Rio Pequeno, próximo à captação da SANEPAR (Figura 3). Estes pontos apresentam características de qualidade de água muito peculiares conforme estudo de evolução de DBO apresentado em Fernandes (2013).

Os pontos IG2E e IG2D ( $25^{\circ} 29^{\prime} 02^{\prime \prime}$ e $49^{\circ} 11$ '23») detalham as margens da seção IG2, e recebem o aporte dos Rios Palmital e Atuba, tipicamente urbanos com grau de tratamento de esgoto de $20 \%$ do total de $40 \%$ coletado em média (FERNANDES, 2013; KNAPIK, 2014).

$\mathrm{O}$ ponto PE1 está situado na derivação de um canal a montante dos pontos IG2E e IG2D, construído para conduzir água das nascentes da Bacia para o Sistema de Distribuição de Água da Região Metropolitana de Curitiba, portanto com características mais adequadas para sistema de captação com baixa concentração de matéria orgânica (KNAPIK, 2014).

\section{Amostragem}

A coleta das amostras de água ocorreu no dia 11 de abril de 2016, às 11h30. 7 litros de água foram amostrados manualmente em cada ponto e transferidos imediatamente para garrafas de polietileno de 1L, previamente descontaminadas (imersão em solução de ácido clorídrico (5\%) por 24 horas), enxaguadas com água pura e secas.

Para minimizar possíveis erros e contaminaçôes, os frascos foram "ambientados" 3 vezes com a própria amostra. Técnicas de preservação básica forma estabele- 


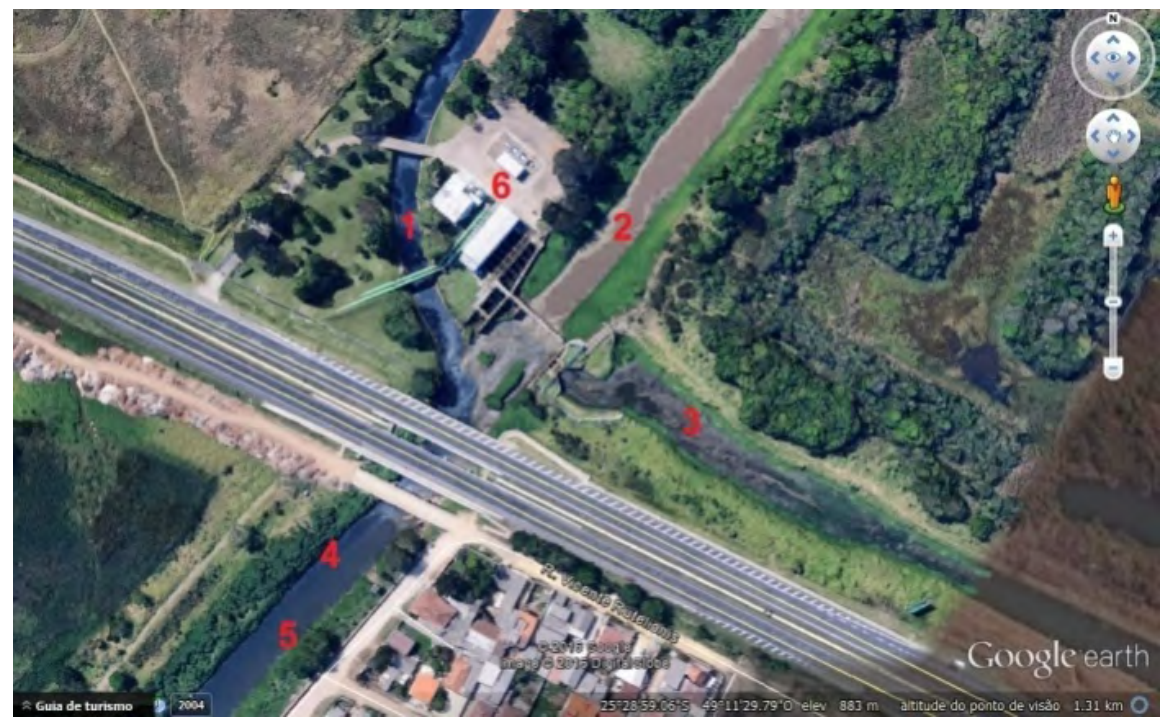

Figura 3- (1-) Rio Atuba; (2) Rio Palmital; (3) PE1; (4) IG2D; (5) IG2E; (6)ETE Atuba Sul

cidas de forma tradicional, considerando a proximidade dos pontos de amostragem com o local de análise.

\section{Técnicas Analíticas}

As amostras foram encaminhadas para o Laboratório de Engenharia Ambiental - Professor Francisco Borsari Neto (LABEAM, UFPR) para a quantificação de DBO pelos métodos Winkler modificado pela azida sódica (método 4500-OC) e método respirométrico/manométrico (5201 B), ambos propostos por APHA (2012).

Os ensaios para a DBO5 iniciaram-se no mesmo dia da coleta e foram monitorados diariamente, durante 5 dias. Nesta esta etapa, foram incubados 5 frascos Winkler para cada ponto avaliado, totalizando 15 frascos, a fim de monitorar o consumo diário de oxigênio, possibilitando calcular o coeficiente de decaimento $\mathrm{k}_{1}$.

Para os devidos fins de comparação foram incubados 3 frascos de garrafa pelo método respirométrico (uma para cada ponto) para mensuração da DBO. Foram colocadas pastilhas de $\mathrm{NaOH}$ em cada equipamento para realizar o cálculo da diferença de pressão.

$\mathrm{O}$ coeficiente $\mathrm{k}_{1}$ foi determinado pelo método da regressão linear (ou mínimos quadrados), a partir dos valores de OD medidos ao longo dos 5 dias de ensaio. A equação 1 foi utilizada para a determinação do coeficiente $\mathrm{k}_{1}$.

$$
L=L_{0} e^{-k_{1} \cdot t}
$$

em que: $\mathrm{L}=\mathrm{DBO}$ remanescente em qualquer ponto ao longo do tempo $\left(\mathrm{mgO}_{2} \cdot \mathrm{L}^{-1}\right) ; \mathrm{L} 0=\mathrm{DBO}$ remanescente em $\mathrm{t}=0$ ou a quantidade total de oxigênio consumido na reação $\left(\mathrm{mgO}_{2} \cdot \mathrm{L}^{-1}\right) ; \mathrm{k} 1$ = coeficiente de desoxigenação $(\mathrm{d}-1) ; \mathrm{t}=$ tempo $(\mathrm{d})$.

\section{RESULTADOS E DISCUSSÃO}

\section{OD e DBO}

Os valores de OD obtidos pelo método Winkler são mostrados na Tabela 1 .

Tabela 1 - Valores de $\mathrm{OD}\left(\mathrm{mgO}_{2} \cdot \mathrm{L}^{-1}\right)$ obtidos através do método winkler modificado pela azida sódica

\begin{tabular}{cccc}
\hline & IG2E & IG2D & PE1 \\
\hline $1^{\circ}$ dia (11/04) & 6,8 & 6,2 & 5,3 \\
$2^{\circ}$ dia (12/04) & 5,5 & 4,7 & 3,5 \\
$3^{\circ}$ dia (13/04) & 5,0 & 3,5 & 3,6 \\
$4^{\circ}$ dia (14/04) & 4,9 & 2,4 & 3,8 \\
$5^{\circ}$ dia (15/04) & 4,9 & 1,4 & 2,6 \\
\hline
\end{tabular}


Como esperado, os valores de OD decaíram após 5 dias e apresentaram algumas particularidades devido à natureza de cada amostra. Cabe destacar que, no ponto IG2D o decaimento ocorreu de forma acentuada, em função da influência direta do lançamento de uma estação de tratamento de esgoto, contendo o tipo de matéria orgânica mais lábil, quando comparado ao IG2E.

Contudo, o valor do OD do último dia (1.4 $\left.\mathrm{mgO}_{2} \cdot \mathrm{L}^{-1}\right)$ indica que o fator de diluição não mostrou-se apropriado para a amostra, pois não atendeu o limite mínimo de $2 \mathrm{mgO}_{2} \cdot \mathrm{L}^{-1}$ exigido pelo método (APHA. 1998)

Entretanto, os pontos IG2E e PE1 tiveram a variação de OD menos acentuada. Para o ponto IG2E, a partir do terceiro dia de ensaio as variaçóes são praticamente estáveis $\left(0.1 \mathrm{mg} \mathrm{O}_{2} \cdot \mathrm{L}^{-1}\right)$. Da mesma maneira, o ponto PE1 apresenta certa estabilidade a partir do segundo dia de ensaio (variação de $0.2 \mathrm{mgO}_{2} \cdot \mathrm{L}^{-1}$ ), apresentando um maior consumo no último dia. Para estes dois pontos, o limite mínimo foi atingido.

Em seguida, foram calculados os valores de DBO5 para os pontos analisados. Na Tabela 2 estáo os resultados obtidos nos três pontos pelo método normalizado e respirométrico.

Tabela 2 - Valores de DBO5 $\left(\mathrm{mgO}_{2} \mathrm{~L}^{-1}\right)$ obtidos através dos métodos normalizado e respirométrico mais o erro associado a cada valor

\begin{tabular}{cccc}
\hline & $\begin{array}{c}\text { Método } \\
\text { Normalizado }\end{array}$ & $\begin{array}{c}\text { Método } \\
\text { Respirométrico }\end{array}$ & $\begin{array}{c}\text { Diferença } \\
\text { percentual }\end{array}$ \\
\hline IG2D & $24,8 \pm 3,7$ & $18,0 \pm 2,7$ & 27,4 \\
IG2E & $10,6 \pm 1,6$ & $8,0 \pm 1,2$ & 24,5 \\
PE1 & $2,8 \pm 0,4$ & $13,0 \pm 2,0$ & 78,5 \\
\hline
\end{tabular}

É possível observar que não há grandes diferenças entre os métodos avaliados para os pontos IG2E e IG2D. O erro associado ao método é estimado em conformidade com APHA (1998), o qual determina uma incerteza de $\pm 30 \mathrm{mg} \mathrm{O}_{2} \mathrm{~L}^{-1}$ em um padrão conhecido de $198 \mathrm{mg} \mathrm{O}_{2} \mathrm{~L}^{-1}$. Esta incerteza apresentada por erro relativo corresponde a aproximadamente $15 \%$, ou seja, a partir de um dado medido de $\mathrm{DBO} 5$, independente do método utilizado, há $15 \%$ de incerteza associado.

A partir desta condição, quando tais incertezas são aplicadas nos valores medidos de $\mathrm{DBO} 5$ (como mostrado na Tabela 2) para o método normalizado e respirométrico, os erros relativos superiores e inferiores para o mesmo ponto de monitoramento adequam-se entre si dentro da incerteza. Todavia, as diferenças percentuais entre os valores medidos nos métodos são, em média, cerca de $25 \%$, estando deste modo fora do erro associado ao método (15\% de acordo com APHA(1998)).

Contudo os valores de DBO5 para o ponto PE1 mensurados a partir do método respirométrico apresentam valores cerca de 5 vezes maiores que os medidos pelo método normalizado, apresentando uma diferença percentual entre os valores medidos de 78,5\%.

Com base em resultados de abordagem metodológica semelhante a desta pesquisa, Jouanneau et al. (2013) afirmam que resultados podem ser diferentes em especial em função de quantificação, custo, confiabilidade e precisão dos resultados.

Entretanto, no estudo de Schulz et al. (2014), foram analisados os métodos respirométrico e luminescente para quantificação de $\mathrm{DBO} 5$ e tais métodos apresentaram uma correlação moderada $\left(\mathrm{R}^{2}\right.$ $=0,5920)$ apenas quando as amostras tinham $\mathrm{OD}$ inicial maior que $8,0 \mathrm{mgO}_{2} \mathrm{~L}^{-1}$ (cerca de 60 amostras). Porém, quando todas as amostras foram consideradas (132 amostras), a correlação decresceu para fraca $\left(\mathrm{R}^{2}=0,2685\right)$. De acordo com autor, esse resultado permite inferir que as duas metodologias não foram equivalentes para as amostras testadas.

Para o presente estudo, também foi verificada a correlaçáo entre os dois métodos analisados, por regressão linear simples (Figura 3). Foram correlacionados os dados de DBO calculados durante os cinco dias de ensaio para cada ponto considerando a variaçáo do erro relativo. $\mathrm{O}$ ponto IG2D apresentou a melhor correlaçáo entre os dados medidos por métodos diferentes $\left(\mathrm{R}^{2}=0.8174\right)$, que pode estar relacionado com a existência de matéria orgânica mais lábil em tal ponto como evidenciado em Knapik (2014). Os demais pontos apresentaram correlações mais baixas (sendo o ponto IG2E com $\mathrm{R}^{2}=0.5411$ e PE1 com $\left.R^{2}=0.4158\right)$, contudo os valores ainda são próximos à correlação moderada apresentada no estudo de Schulz et al. (2014).

As diferenças de quantificação já são esperadas para os métodos de determinação de $\mathrm{DBO}$, contudo fatores adicionais podem aumentar significativamente os erros associados (como observado para o ponto PE1). 


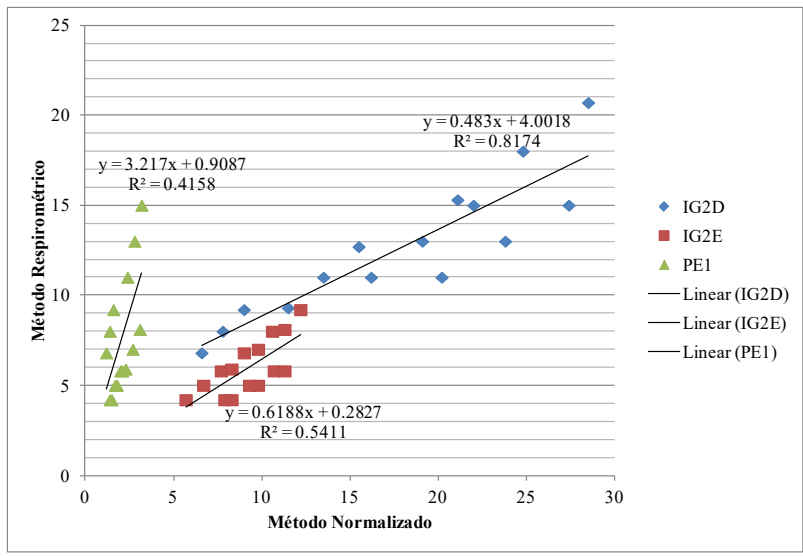

Figura 3 - Correlação linear entre o método normalizado e o método respirométrico para os pontos IG2D, IG2E e PE1 analisados

Alguns destes fatores observados são: erros analíticos associados aos sensores respirométricos, mudança de analisador, troca de reagentes, diluição correta, incubação de amostra com semente e/ou erros operacionais que envolvem os processos de coleta das amostras, ambientação e homogeneização, entre outros. Mesmo com todo o rigor e cuidado analítico envolvido na determinação da $\mathrm{DBO}$, o método apresenta fragilidades peculiares que merecem atenção redobrada, visto que a DBO é o principal parâmetro utilizado na gestão dos recursos hídricos (por exemplo: enquadramento dos corpos hídricos e outorga de uso).

\section{Coeficiente de Desoxigenação Carbonácea $\left(\mathbf{k}_{1}\right)$}

Uma vez que os valores de OD ao longo dos cinco dias são conhecidos, é possível calcular o coeficiente $\mathrm{k}_{1}$ ajustando uma curva por regressão linear, utilizando ajuste de mínimos quadrados para avaliação da decomposição da Matéria Orgânica, conforme resultados apresentados na Tabela 3 .

Tabela 3 - Valores do coeficiente de desoxigenação para cada ponto de amostragem

\begin{tabular}{ccc} 
Pontos & $\mathrm{k} 1\left(\mathrm{~d}^{-1}\right)$ & $\mathrm{R}^{2}$ \\
\hline IG2E & 0,09 & 0,73 \\
IG2D & 0,28 & 0,90 \\
PE1 & -0.04 & 0,02 \\
\hline
\end{tabular}

Como pode ser observado, os valores de $\mathrm{k}_{1}$ para os pontos do IG2 apresentam coeficientes de 0,09 para o ponto IG2E e 0,28 para o ponto IG2D. Considerando os valores típicos de $\mathrm{k}_{1}$ apresentado por Von Sperling (2005), o ponto IG2E possui um comportamento de desoxigenação típico de cursos $\mathrm{d}$ 'água com águas limpas $\left(\mathrm{k}_{1}\right.$ varia entre $0,08-0,20$ $\mathrm{d}^{-1}$ ), enquanto o IG2D apresenta o valor de coeficiente de desoxigenaçáo similar aos de efluentes secundários $\left(\mathrm{k} 1\right.$ varia entre $\left.0,12-0,24 \mathrm{~d}^{-1}\right)$.

Como pode ser observado, os valores de $\mathrm{k}_{1}$ para os pontos do IG2 apresentam coeficientes de 0,09 para o ponto IG2E e 0,28 para o ponto IG2D.

Isto está diretamente relacionada à existência de uma estação de tratamento de esgoto localizada a montante do ponto IG2D, influenciando diretamente na qualidade da água neste local. E, devido aos processos de mistura que ainda não foram completados neste determinado local de coleta, o ponto IG2E não é diretamente influenciado. No estudo desenvolvido por Knapik (2014), nos mesmos pontos de estudo deste trabalho, também foram determinados coeficientes de desoxigenação. Os valores obtidos representam o mesmo comportamento, apesar dos valores distintos, por exemplo, na campanha de número 39 do estudo o ponto IG2E apresentou $k_{1}$ de 0,26 e o ponto IG2D apresentou $\mathrm{k}_{1}$ de 0,47 , e na campanha $42 \mathrm{com} \mathrm{k}_{1}$ de 0,82 para IG2E e 0,93 para IG2D, atribuindo uma desoxigenaçáo mais acentuada no ponto localizado na margem direita. Collischonn (2008) cita valores de $\mathrm{k}_{1}$ entre 0,1 e $0,35 \mathrm{~d}^{-1}$ para testes em bancada a partir 
de diferentes amostras considerando amostras de rios e efluentes náo tratados.

Contudo, o ponto PE1 apresenta um coeficiente $\mathrm{k}_{1}$ de $-0,04$, o qual foi obtido a partir da regressão linear com $R^{2}=0.02$. Tais valores apresentam uma correlação baixa. Associado à grande diferença percentual entre os valores calculados nos métodos propostos $(-78 \%)$ para o ponto $\mathrm{PE} 1$, as discrepâncias envolvidas podem estar associadas ao erro em algum dos procedimentos analíticos aplicados.

Em relação às curvas ajustadas (Figuras 4, 5 e 6), é possível observar que o comportamento da DBO exercida para os pontos IG2E e IG2D atendem a um comportamento padrão (aumentando rapidamente nos primeiros dois dias e, em seguida, estabilizando aos poucos), com coeficientes de correlação de $\mathrm{R}^{2}=0,89$ para IG2D e $\mathrm{R}^{2}=0,73$ para o IG2E; Em contrapartida, o ponto PE1 $\left(\mathrm{R}^{2}=0,02\right)$ apresenta comportamento instável.

O processo de consumo de OD é bem representado por modelos cinéticos de primeira ordem, visto que a taxa de reação é proporcional à concentração da substância analisada (COLLISCHONN, 2008). Contudo, quando se estima um coeficiente de desoxigenação para verificar a intensidade deste consumo de OD é necessário verificar os fatores que alteram tais estimativas. Knapik (2014) discorre sobre fatores associados à característica da matéria orgânica (lábil ou refratária), bem como os associados aos ensaios de $\mathrm{DBO}$, como variaçóes na temperatura da incubação, presença de luz, condiçôes anóxicas, rápido consumo e até mesmo a falta de microorganismos suficientes para o consumo.

\section{Análise Crítica dos Métodos}

Mediante a todos os dados e informaçóes obtidas ao longo dos cinco dias de análise, nota-se uma discrepância entre os resultados obtidos para um mesmo parâmetro por diferentes métodos de análise quando há um ponto com grandes influências orgânicas e outro não. Isso demonstra a fragilidade e as incertezas agregadas a esta análise, para ambos os métodos, como evidenciado no ponto PE1. O uso de sensores manométricos, por exemplo, representa um fator simplificador quando comparado aos processos de titulaçáo envolvidos no método normalizado. Entretanto, é necessário garantir sempre que a calibraçáo dos sensores esteja adequada.

Todas as fragilidades do método já são conhecidas, bem como outras maneiras de se calcular a matéria orgânica presente em corpos d'água, como por meio da análise do carbono orgânico e técnicas de espectroscopia de fluorescência (KNAPIK, 2016) . No entanto, o teste de $\mathrm{DBO}$ ainda é o mais utilizado, considerando seu baixo custo operacional comparativamente ao COT. De forma adicional, a legislação ainda contempla dentro de sua normativa o teste de DBO para uso na gestão de recursos hídricos, destacando a relevância dos controles analíticos para a sua adequada utilização.

\section{CONSIDERAÇÕES FINAIS}

É possível concluir que os métodos de análise de $\mathrm{DBO}$, normalizado e respirométrico, apresentam diferenças entre si, todavia os valores analisados dentro do erro relativo ao próprio método $( \pm 15 \%)$ adéquam-se entre si para os pontos IG2D e IG2E. Contudo, em relação ao ponto $\mathrm{PE} 1$ as diferenças percentuais foram de $-78 \%$.

Em concordância com a metodologia de análise winkler, o ponto IG2D apresentou valores de OD inferiores a 2,0 $\mathrm{mgO}_{2} \cdot \mathrm{L}^{-1}$ no último dia de análise, o que invalidaria a aplicação do método, visto que os limites máximo e mínimos para detecção de $\mathrm{OD}$ variam de 9,0-2,0 mg. $\mathrm{L}^{-1}$. Possivelmente, essa baixa concentraçáo deve-se a erros analíticos que foram identificados apenas no último dia de ensaio, inviabilizando a repetição da análise.

Ao final do experimento, comprovou-se na prática as incertezas operacionais associadas aos métodos, que os tornam subjetivo e de difícil precisão. Encontrar um fator de diluiçáo para as amostras representou uma dificuldade no método winkler, pois estabelecer um fator de diluição ótimo no qual a amostra não fique muito diluída e nem muito concentrada requer tempo, experiência e controle de custo adicionado aos reagentes, vidrarias, entre outros.

Neste contexto, mesmo considerando sua relevância conceitual, faz-se necessário estudos comparativos, inter-laboratoriais e otimização de outras técnicas analíticas, como análises integradas de DBO com carbono orgânico dissolvido e total, análises de espectroscopia de fluorescência para indicar o tipo de matéria orgânica predominante no meio, entre outros. Ademais, o refinamento do analisador em si, proporciona a estabilidade na realização do procedimento analítico devido à experiência adquirida. 


\section{Referências}

APHA - AMERICAN PUBLIC HEALTH ASSOCIATION. Standard methods for the examination of water and wastewater. 20. ed. Washington, 1998.

BARROS, F. M.; MARTINEZ, M.A.; MATOS, A. T.; ROCHA, F.A.; SILVA, D.P. Reoxigenação e desoxigenação no rio Turvo Sujo. ENCICLOPÉDIA BIOSFERA, Centro Científico Conhecer - Goiânia, v. 7, n.12, 2011.

BRASIL. Lei Federal n 9.433, de 8 de janeiro de 1997. Institui a Política Nacional de Recursos Hídricos, cria o Sistema Nacional de Gerenciamento de Recursos Hídricos, regulamenta o inciso XIX do art. 21 da Constituição Federal, e altera o art. $1^{\circ}$ da Lei n 8.001, de 13 de março de 1990, que modificou a Lei n 7.990, de 28 de dezembro de 1989. Diário Oficial da União, Brasília, DF, 8 jan. 1997.

BRASIL. Conselho Nacional do Meio Ambiente - CONAMA. Resolução n 357, de 17 de março de 2005. Estabelece a classificação das águas doces, salobras e salinas do Território Nacional. Diário Oficial da União, Brasília, DF, 18 mar., 2005.

CALDWELL, D.H.; LANGELIER, W.F. Manometric measurement of the biochemical oxygen demand of sewage. Sewage Works Journal, v. 20, n. 2, p. 202-218, 1948.

CHAPRA, S. C. Surface water-quality modeling. Boston: WCB/ McGraw-Hill, 1997.

COELHO, M. Avaliação da poluição orgânica e biodegradabilidade nos rios urbanos da bacia do Alto lguaçu. 2010. 120 f. Trabalho de conclusão de curso (Graduado em Engenharia Ambiental) - Universidade Federal do Paraná, Curitiba, 2010.

COLLISCHONN, W. Introduzindo hidrologia: qualidade da água. 2008. cap. 19.

FERNANDES, C. V. S. INTEGRA 2: bases técnicas para a integração de instrumentos de gestão de recursos hídricos: estudo de caso da Bacia do Alto Iguaçu e Bacia do Alto Tietê. Curitiba: Universidade Federal do Paraná, 2013.

JOUANNEAU, S.; RECOULES, L.; DURAND, M. J.; BOUKABACHE, A.; PICOT, V.; PRIMAULT, Y.; LAKEL, A.; SENGELIN, M.; BARILLON, B.; THOUAND, G. Methods for assessing biochemical oxygen demand (BOD): A review. Water Research, v. 9, p.62-82, 2014. Disponível em: http://dx.doi.org/10.1016/j.watres.2013.10.066. Acesso em: 10 set. 2015.

KNAPIK, H. G. Organic matter characterization and modeling in polluted rivers for water quality planning and management. 2014. 281 f. Tese (Doutorado em Engenharia de Recursos Hídricos e Ambiental) - Universidade Federal do Paraná, Curitiba, 2014.

KNAPIK, H. G. Reflexões sobre Monitoramento, Modelagem e Calibração na Gestão de Recursos Hídricos: Estudo de Caso da Qualidade da Água da Bacia de Recursos Hídricos. 2009. 180 f. Dissertação (Mestrado em Engenharia de Recursos Hídricos e Ambiental) - Universidade Federal do Paraná, Curitiba, 2009.

KONDAGESKI, J. H. Calibração de Modelo de Qualidade da Água para Rio Utilizando Algoritmo Genético. Dissertação (Mestrado em Engenharia de Recursos Hídricos e Ambiental) - Universidade Federal do Paraná, Curitiba, 2008.

LEENHEER, J. A.; CROUÉ, J. P. Characterizing dissolved aquatic organic matter. Environmental Science and Technology, v. 37 (1), p. 18-26, 2003. 
METCALF \& EDDY, INC. Wastewater Engineering: Treatment and Reuse. 3. ed. New York: McGraw-Hill, 1991.

PRZYBYSZ, L. C. B. A Gestão de Recursos Hídricos sob ótica do Usuário - Estudo de Caso da Bacia do Alto Iguaçu. 2007. Dissertação (Mestrado em Engenharia de Recursos Hídricos e Ambiental) - Universidade Federal do Paraná, 2007.

SANTOS, E. O.; SALES, P. R.; DUARTE, M. M. M. Estudo comparativo entre as técnicas de diluição e manométrica na quantificação da demanda bioquímica de oxigênio. In: CONGRESSO BRASILEIRO DE ENGENHARIA SANITÁRIA E AMBIENTAL, 22, 2003, Joinville. Santa Catarina, 2003.

SCHULZ, F.; MOLZ, C. H.; MIRANDA, L. A. S.; PIRES, A. C. P. Avaliação metodológica na determinação de DBO5 por respirometria e luminescência. In: SIMPÓSIO INTERNACIONAL DE QUALIDADE AMBIENTAL, 9, 2014, Porto Alegre: ABES, 2014.

SPERLING, M. V. Introdução à qualidade das águas e ao tratamento de esgotos. Belo Horizonte, MG, 2005 .

STAMER, J. K.; BENNETT, J. P.; MCKENZIE, S. W. Determination of ultimate carbonaceous BOD and the specific rate constant (K1). U.S. Geological Survey. Open-File Report p. 82-645, 1983.

VALENTE, J. P. S; PADILHA, P. M.; SILVA, A. M. M. Dissolved Oxygen (DO), biochemical oxygen demand (BOD) and chemical oxygen demand (COD) as pollution parameters in the Lavapés/Botucatu - SP. Eclética Química, v.22, p.49-66, 1997. Disponível em: http://ref.scielo.org/5xph9g. Acesso em: 16 set. 2016.

Ellen C. de Oliveira Almeida Universidade Federal do Paraná,

Curitiba, PR, Brasil. E-mail: carolkozak05@gmail.com

Contribuição do autor:

Pesquisa de campo; análise dos dados; redação

Caroline Kozak Universidade Federal do Paraná,

Curitiba, PR, Brasil. E-mail: carolkozak05@gmail.com

Contribuição do autor:

Indicação e seleçấo de fontes de dados; análises de dados.

Luciane L. Prado

Universidade Federal do Paraná,

Curitiba, PR, Brasil. E-mail: lulepr1074@gmail.com

Contribuição do autor:

Indicação e seleção de fontes de dados; análises de dados.

Cristovão S. Fernandes

Universidade Federal do Paraná,

Curitiba, PR, Brasil. E-mail: cvs.fernandes@gmail.com

Contribuição do autor:

análise dos dados; redação e fechamento do manuscrito 